\title{
Malnutrition and Associated Factors among Adult Individuals Receiving Highly Active Antiretroviral Therapy in Health Facilities of Hosanna Town, Southern Ethiopia
}

\author{
Mekuria Asnakew*, Chernet Hailu, Habtamu Jarso \\ Department of Epidemiology, College of Public Health and Medical Sciences, Jimma University, Jimma, Ethiopia \\ Email: "mekas63@yahoo.com, Chernet mengesha@yahoo.com, hjarso@rockermail.com
}

Received 10 January 2015; accepted 25 January 2015; published 29 January 2015

Copyright (C) 2015 by authors and OALib.

This work is licensed under the Creative Commons Attribution International License (CC BY). http://creativecommons.org/licenses/by/4.0/

(c) (i) Open Access

\section{Abstract}

Background: In resource limited settings, many human immunodeficiency virus (HIV) infected individuals lack access to sufficient quantities of nutritious foods, which poses additional challenges to the success of anti-retroviral therapy. Morbidity and mortality related to human immune deficiency virus infection in the developing world remain unacceptably high, despite major advances in human immune deficiency virus therapy and increased international funding for care. Objective: To determine magnitude of malnutrition and identify factors associated with it among adult people on highly active anti-retroviral therapy (HAART) in health facility of Hosanna town. Methods: Institutional based cross-sectional survey was conducted from March 20 to April30, 2014 on 340 adult people on anti-retroviral therapy at antiretroviral therapy clinics of Hosanna town. Sample clients were selected by simple random sampling technique. Data were collected by face-to-face interview using structured pretested questionnaire, record review using check list and anthropometric measurements. Bi-variate analysis and multivariable logistic regression models were done using SPSS version 16 to identify factors associated with malnutrition. Results: Overall, the prevalence of malnutrition (Body Mass Index (BMI) $<18.5 \mathrm{~kg} / \mathrm{m}^{2}$ ) in this study was $31.2 \%$. Household food insecurity (AOR $=2.51,95 \% \mathrm{CI}: 1.31-4.81$ ), inadequate diversified diet (AOR $=0.44$, 95\% CI: $0.23-0.84$ ), low meal frequency (AOR $=0.29,95 \%$ CI: $0.11-0.76)$, clinical staging four $(A O R=5.23,95 \%$ CI: 1.42 - 19.35), clinical staging three $(A O R=3.91,95 \%$ CI: 1.57, 9.73), presence of opportunistic infections (AOR $=2.62,95 \%$ CI: 1.49 - 4.59) and nutritional support (AOR $=0.45$, 95\% CI: 0.23 - 0.89) were independent predictors of malnutrition. Conclusion: Malnutrition (BMI < $18.5 \mathrm{~kg} / \mathrm{m}^{2}$ ) was high in adult people on anti-retroviral therapy at anti-retroviral therapy clinics of Hossana town. Only Anti-Retroviral Therapy is not enough to improve the health status of people on HAART. Further, interventional initiatives should focus in improving household food security, diversity of diet, meal frequency, clinical staging and prevention and control of opportunistic infections in adult HIV infected individuals receiving highly active anti-retroviral therapy.

\footnotetext{
"Corresponding author.
}

How to cite this paper: Asnakew, M., Hailu, C. and Jarso, H. (2015) Malnutrition and Associated Factors among Adult Individuals Receiving Highly Active Antiretroviral Therapy in Health Facilities of Hosanna Town, Southern Ethiopia. Open Access Library Journal, 2: e1289. http://dx.doi.org/10.4236/oalib.1101289 


\title{
Keywords
}

\section{Anti-Retroviral Therapy, Human Immune Deficiency Virus, Malnutrition}

\author{
Subject Areas: Nutrition
}

\section{Background}

Malnutrition literally means "bad nutrition" and technically includes both over- and under-nutrition. In the context of developing countries, under-nutrition is generally the main issue of concern, though industrialization and changes in eating habits have increased the prevalence of over nutrition. Nonetheless, within the context of World Food Programme (WFP) programs and assessments, malnutrition refers to under-nutrition unless otherwise specified [1]. Likewise, in this study the issue is the under-nutrition. It is the outcome of a group of factors such as poverty, inadequate access to food, illiteracy, large family size, poor environmental sanitation, chronic illness such as Acquired Immune Deficiency Syndrome (AIDS), lack of safe drinking water, and lack of awareness on nutritional related issue [2]. It is also results from imbalance of nutrient intake with physiological demand for growth, maintenance and reproduction [3].

The HIV epidemic remains one of the main public health challenges especially in low and middle income countries. At the end of 2010, globally an estimated 34 million people were living with HIV/AIDS with 2.7 million new HIV infections and the annual number of people dying from AIDS related causes was 1.8 million. The majority of adults newly infected with HIV are in Sub-Saharan Africa (SSA). In SSA, an estimated 1.9 million people become infected with HIV in 2011. Ethiopia is one of the seriously affected countries in SSA with a large number of people (approximately 800,000) living with HIV/AIDS and 44,751 AIDS-related deaths [4]. According to the 2011 Ethiopian demographic and health survey (EDHS), HIV prevalence in Ethiopia is 1.9\% for women and $1.0 \%$ for men with an overall prevalence of $1.5 \%$. This is essentially unchanged from the HIV Prevalence reported in 2005 (1.4\%) [5].

The effect of HIV/AIDS pandemic on nutritional status of infected people is widely known. The common known effects are severe muscle wasting and underweight [6]. More than 800 million people worldwide are chronically undernourished from which 200 millions are living in SSA, and greater than 33 million are living with HIV infection [4]. A meta-analysis study conducted in Sub-Saharan countries reported that the pooling prevalence estimates of HIV-related under-nutrition (BMI $<18.5 \mathrm{~kg} / \mathrm{m}^{2}$ ) for women was $10.3 \%$ and the prevalence in Ethiopian was 13.2\%; similar data for African men not available [7].

The availability of Highly Active Antiretroviral Therapy (HAART) has extended the lives of many people with HIV/AIDS \& greatly reduced morbidity and death due to AIDS \& related complications [8]. However, morbidity and mortality related to HIV infection in the developing world remain unacceptably high, despite major advances in HIV therapy and increased international funding for care [9].

Poor nutritional status and food insecurity may hasten progression to AIDS, undermine adherence and response to antiretroviral therapy. Research shows that, within households affected by HIV, there is an increased risk of food insecurity as sick members are unable to work, income declines, expenditure on health care increases and care-giving burdens increase [10].

Inadequate dietary intake to meet the increased metabolic demands associated with HIV infection is likely to affect nutritional status in Peoples living with HIV/AIDS (PLWHA), further lowering their immunity and hastening disease progression hence increasing morbidity and mortality [11].

In resource limited settings, many PLWHA lack access to sufficient quantities of nutritious foods, which poses additional challenges to the success of Anti Retroviral Therapy (ART) [12] [13].

Limited evidences exist that show the prevalence of malnutrition and identify associated factors among adult people on HAART in Ethiopia and no previous studies conducted in health facility of Hosanna town. In addition, previous studies conducted in Ethiopia only focused on clinical factors and didn't include some important factors such as dietary factors and food insecurity which may determine nutritional status among people on HAART. Therefore, this study explored magnitude of malnutrition and associated factors among adult people on antiretroviral therapy in health facility of Hosanna town, Hadiya zone, Southern Ethiopia. 


\section{Methods}

\subsection{Study Design, Area and Study Population}

Facility based cross sectional study was conducted among adult people on HAART at ART clinics of Hosanna town. The study was conducted from March 20 to April 30/2014 in Hosanna town, which is $230 \mathrm{~km}$ far from Addis Ababa in the south west direction. There are only two ART care units in the town at Nigist Elenie memorial Hospital and Hosanna health centre. A total of 3773 clients were present on pre ART and ART care units at the two ART care units. The source population was all adult people who are enrolled in highly active anti-retro viral therapy at ART clinics of Hosanna town and the study population was selected adult people on antiretroviral therapy at ART clinics of Hosanna town during the study period that fulfils the inclusion criteria. The study include all adult people on antiretroviral therapy willing to participate and age of 18 years and more and exclude individuals who were seriously ill and un-able to get through the interview. Pregnant women were also excluded from the study since weight gain during pregnancy introduces measurement bias.

\subsection{Sample Size Determination and Sampling Procedure}

The required sample size was determined using single population proportion formula,

$$
\mathbf{n}=\frac{\left(\mathbf{Z}_{\left(\frac{\boldsymbol{a}}{2}\right)}\right)^{2} \mathbf{P}(1-\mathbf{P})}{\mathbf{d}^{2}}
$$

considering the following assumptions: $\mathbf{p}=\mathbf{2 7 . 8} \%$ (proportion of malnourished people on HAART) [14], Z $\mathbf{a} / \mathbf{2}$ is the value of the standard normal distribution corresponding to a significant level of alpha $(\boldsymbol{\alpha})$ of $\mathbf{0 . 0 5}$, which is $\mathbf{1 . 9 6}$ and desired degree of precision (d) of $\mathbf{5 \%}$, the computed sample size was 309 and by adding $\mathbf{1 0 \%}$ non response rate, the total sample size computed was $\mathbf{3 4 0}$. Before data collection a list of eligible ART clients were identified from ART data base. According to the total number of ART clients in each clinic, proportionate number of sample clients was assigned for each ART clinics. Study participants were selected by simple random sampling technique using random number computer generation method.

\subsection{Data Collection}

Data were collected using face to face interview, record review and anthropometric measurements. Four ART adherence counsellors as data collectors and one health officer as supervisor were recruited.

\subsection{Data Processing and Analysis}

Data was edited, coded and entered in to Epi data 3.1 and exported to SPSS window version 16.0 for analysis. Further, data cleaning (editing, recoding, checking for missing values, and outliers) was made after exported to SPSS.

The data analysis ranges from the basic description to the identification of potential predictors of malnutrition. Bi-variate analysis and multivariable logistic models was used to show the relation between malnutrition and various associated factors.

The basic descriptive summaries of patients' characteristics and outcome of interest was computed. Accordingly, simple frequencies, measure of central tendencies and measure of dispersions were computed.

Finally, all explanatory variables that results $(\mathrm{P}<0.25)$ with the outcome variable were entered in to multivariable logistic regression model using backward likely hood ratio method to identify independent predictor of malnutrition. P-value $<0.05$ was considered as statistically significant and odds ratio at $95 \%$ confidence interval is used to examine the precision and strength of association.

\subsection{Measurements}

Socio-demographic and lifestyle factors: age, sex, residence, employment status, educational level, occupation, source of drinking water, marital status, head of the house hold, social support ,disclosure status, life style and family size was collected using pre-tested structured questionnaire. 
Economic status: Data were collected on ownership of selected assets, such as television, radio, livestock, etc. to measure wealth index.

Health care related factors: gastrointestinal symptoms' in the last two weeks and adherence in the last month were collected using pre-tested structured questionnaire while, side effect of ART, duration of ART, opportunistic infections (OIs) and CD4 cell count in the past 6 months and AIDS' clinical stage was collected from record using check list.

Individual Dietary Diversity Score (IDDS): a record of the 24 hour recall of all food groups eaten by the respondents was taken and classified into the 12 food groups using the FAO/Nutrition and Consumer Protection Division recommended questionnaire [15].

For meal frequency daily eating occasions over the 24-hour period was asked and recorded [16].

Nutritional counseling and nutritional support was collected using pre-tested structured questionnaire.

Food Insecurity was assessed by using a short version of the Household Food Insecurity Access Scale (HFIAS) developed by the Food and Nutrition Technical Assistance (FANTA) project. Occurrence questions relate to three different domains of food insecurity will be used. I. Anxiety and uncertainty about the household food supply. II. Insufficient quality (includes variety and preferences of the type of food). III. Insufficient food intake and its physical consequences. Each of the questions is asked with a recall period of four weeks (30 days). The respondent is first asked an occurrence question that is, whether the condition in the question happened at all in the past four weeks (yes or no). If the respondent answers "yes" to an occurrence question, a frequency-of-occurrence question will be asked to determine whether the condition happened rarely (once or twice), sometimes (three to ten times) or often (more than ten times) in the past four week [17].

Anthropometric measurement consists of client's weight and height. Participants' weight was measured by seka weight scale calibrated to $0.5 \mathrm{~kg}$ after removing heavy clothes. Participants' height was measured using seka measuring rod calibrated to $0.5 \mathrm{~cm}$. Participants were take off their shoes, stand erect, and look straight in horizontal plain to measure their Height [18].

Body mass index (BMI): was calculated as weight in kilograms divided by the square of height in meters $\left(\mathrm{kg} / \mathrm{m}^{2}\right)$.

Dietary diversity: was computed and dichotomized into two categories; which is low dietary diversity score and high dietary diversity score. The calculated chronbach's alpha was 0.73 .

Food security status: was computed and dichotomized into two categories; which is food insecure and food secure. The calculated chronbach's alpha was 0.88 .

Wealth analysis: initially, reliability test was performed using the economic variables involved in measuring the wealth of the households. The calculated Chronbach's alpha was 0.79 . The variables which were employed to compute the alpha value were entered in to the principal component analysis.

At the end of the principal component analysis, the wealth index was obtained as a continuous scale of relative wealth. Finally, tercile of the wealth index were created to see the association with malnutrition.

\subsection{Data Quality Control}

The questionnaire was adapted from previous literatures \& modified in to the study context. It was prepared first in English and translated into Amharic, and then retranslated back to English by an expert who is fluent in both languages to maintain its consistency.

Training was given for data collectors and supervisor on objective of the research, how to collect the data through interviewing approach, anthropometric measurement and data recording. During the training, the trainer was demonstrated how to take anthropometric measurements and the trainee was demonstrated it in front of the trainer using small sample of clients. Pre testing of the questionnaire was made on 17 ART care clients in the nearby wereda health centre a week prior to the actual survey. Consequently, based on the feedback obtained from the pre-test, questions which need clarification revised.

Daily the data was strictly revised for completeness, accuracy and clarity by the supervisors and principal investigator. In addition, the data were thoroughly cleaned and carefully entered in to computer using Epi data version 3.1 using double entry verification. Weight of participants was taken using standard beam balance and the scale was checked at zero before and after each measurement. And also, height measurement of participants was taken using the standard measuring scale. 


\subsection{Ethical Consideration}

Prior to data collection, ethical approval were obtained from ethical review committee of Jimma University, College of Public Health and medical sciences and submitted to Hadiya zone Health Bureau, Nigist Elienie Mohammed Hospital, Hosanna health centre administrators and other concerned bodies to obtain their co-operation. Verbal consent was taken from each participant after the purpose of the study explained. They were told to withdraw at any time from responding to questions if they are not interested to respond. Participants were informed that all the data obtained from them will be kept confidential using codes instead of any personal identifiers.

\section{Results}

\subsection{Socio-Economic and Lifestyle Characteristics}

A total of 330 adult PLWHA taking ART were participated in the study giving a response rate of $97.1 \%$. The rest $2.9 \%$ were excluded because of incomplete information.

Out of 330 participants, female accounts 214 (64.8\%). The mean age of respondents was 34.78 (SD: 9.42) and $135(40.9 \%)$ of them were in the age range of (30 - 39). Majority of respondents $215(65.2 \%)$ living in urban. Two hundred (60.6\%) of them headed by male, and only 93 (28.2\%) of them live with a family size of greater than or equal to five. Among the participants, 166 (50.3\%) were married, and fifty one (15.5\%) windowed. Regarding educational status, 149 (45.2\%) completed grade 1 - 8, and 102 (30.9\%) completed grade 9 - 12. Concerning their occupation, about one fourth 87 (26.4\%) of respondents were unemployed, and 69 (20.9\%) were self employed. Majority of respondents, 193 (58.5\%) were from ethnic group Hadiya, and 196 (59.4\%) were followers of protestant religion. Only 48 (14.5\%) of them got social support (Table 1).

Concerning their living condition, 161 (48.8\%) of individuals living with their spouse and 38 (11.5\%) were living alone. One hundred ninety eight (60\%) of respondents did disclose their HIV status. Majority 269 (87.6\%) of respondents were got drinking water from pipe water (public and private tap) (Table 2).

Regarding wealth status, 124 (37.6\%) of individuals were poor (Table 2).

Regarding life style conditions only: 7 (2.1\%) of individuals were smoking cigarette; 15 (4.5\%) of individuals were doing physical exercise; 12 (3.6\%) of individuals were chewing chat; and 10 (3\%) of individuals were drinking alcohol (Table 2).

\subsection{Health Status Related Factors}

Out of 330 respondents, 279 (84.5\%) of them were receiving care and treatment at the Hospital. Larger proportion of the respondents 248 (75.2\%) were following ART care for more than twelve months (Table 3).

Regarding to gastro intestinal symptoms, 139 (42.12\%) of them faced a gastro intestinal symptoms during the past two weeks before the survey. Concerning to opportunistic infections, 133 (40.3\%) were diagnosed with opportunistic infections during the past six month before the survey. Among these 31 (23.30\%) were diagnosed with tuberculosis, 78 (58.60\%) were diagnosed with oral candidiasis and 60 (45\%) were diagnosed with diarrhea during the past six month before the survey. Fifty five (16.7\%) respondents faced side effect of ART during the past two weeks before the survey. Regarding to clinical staging, 17 (5.15\%) were at stage four and one hundred six (32.12\%) were at stage three during the survey (Table 3 ).

Larger proportion (85.5\%) of respondents had good adherence to ART during the past one month before the survey. However, 14 (4.2\%) individuals had poor adherence to ART.

Out of 330 respondents, 44 (13.3\%) had CD4 count $<200$ cells/ $\mu 1,103$ (31.2\%) had CD4 count $200-350$ cells $/ \mu$, and $183(55.5 \%)$ had CD4 count $>350$ cells/ $\mu$ l during the past six month before the survey (Table 3 ).

\subsection{Dietary Characteristics of Respondents}

Majority of respondents, 271 (82.1\%) didn't get nutritional support and 209 (63.3\%) of them were counselled about dietary feeding (Table 4). Out of 330 participants, larger proportion of the respondents (67.9\%) had inadequate diversified food and (84.2\%) had low meal frequency score with in the 24 hour dietary recall period (Table 4). 
Table 1. Socio-demographic characteristics of respondents taking antiretroviral therapy in health facility of Hosanna town, Hadiya zone, South Ethiopia, from March 20 to April 30/2014.

\begin{tabular}{|c|c|c|}
\hline Characteristics & Category & Number (\%) \\
\hline \multirow{2}{*}{ Sex of the participant } & Male & $116(35.2)$ \\
\hline & Female & 214 (64.8) \\
\hline \multirow{4}{*}{ Age category } & $18-29$ & 103 (31.2) \\
\hline & $30-39$ & 135 (40.9) \\
\hline & $40-49$ & $63(19.1)$ \\
\hline & $>=50$ & $29(8.8)$ \\
\hline \multirow{2}{*}{ Place of residence } & urban & 215 (65.2) \\
\hline & Rural & $115(34.8)$ \\
\hline \multirow{4}{*}{ Marital status } & married & $166(50.3)$ \\
\hline & Single & $77(23.3)$ \\
\hline & Divorced & $36(10.9)$ \\
\hline & Windowed & $51(15.5)$ \\
\hline \multirow{5}{*}{ Educational level } & Can't read and write & $34(10.3)$ \\
\hline & Can read and write & $14(4.2)$ \\
\hline & Grade 1 - 8 & $149(45.2)$ \\
\hline & Grade 9 - 12 & 102 (30.9) \\
\hline & College and above & $31(9.4)$ \\
\hline \multirow{4}{*}{ Religion } & protestant & $196(59.4)$ \\
\hline & Orthodox & $87(26.4)$ \\
\hline & Muslim & $38(11.5)$ \\
\hline & Others ${ }^{*}$ & $9(2.73)$ \\
\hline \multirow{5}{*}{ Ethnic group } & Hadiya & 193 (58.5) \\
\hline & Kenbata & $32(9.7)$ \\
\hline & Amhara & $50(15.2)$ \\
\hline & gurage & $29(8.8)$ \\
\hline & Others $^{* *}$ & $26(7.9)$ \\
\hline \multirow{5}{*}{ Occupation } & farmer & $61(18.5)$ \\
\hline & Government employed & $61(18.5)$ \\
\hline & Self employed & $69(20)$ \\
\hline & Unemployed & $87(26.4)$ \\
\hline & Others+ & $52(15.8)$ \\
\hline \multirow{2}{*}{ Head of the house hold } & Male & $200(60.6)$ \\
\hline & Female & 130 (39.4) \\
\hline \multirow{2}{*}{ Family size } & $<=5$ & 237 (71.8) \\
\hline & $>5$ & $93(28.2)$ \\
\hline
\end{tabular}

*Adventist (1), catholic (8) + daily labor (25), house wife (27); ** Silte (21), Oromo (10), Tigre (5) and wolayta (16).

\subsection{Food Security Status of Respondents}

Out of 330 participants, larger proportions of the respondents (68.5\%) were food insecure (Figure 1).

\subsection{Prevalence of Malnutrition among People on HAART}

Overall, the prevalence of malnutrition with (BMI $\left.<18.5 \mathrm{~kg} / \mathrm{m}^{2}\right)$ in this study was (31.2\%). Females were most affected (18.79\%). Out of 103 malnourished individuals, 6 (5.83\%) were severely malnourished, 18 (17.48\%) were moderately malnourished, and 79 (76.69\%) were mildly malnourished (Figure 2). The mean BMI of the respondents was 20.24 with SD of \pm 2.57 .

\subsection{Factors Associated with Malnutrition among Individuals Receiving HAART}

Before the multi-variable analysis regression diagnostic procedures were carried out under linear regression by 
Table 2. Socio-economic and life style characteristics of respondents taking antiretroviral therapy in health facility of Hosanna town, Hadiya zone, south Ethiopia, from March 20 to April 30/2014.

\begin{tabular}{ccc}
\hline Characteristics & Category & Number (\%) \\
\hline Social support & yes & $48(14.5)$ \\
& No & $282(85.5)$ \\
Disclosure status & yes & $198(60)$ \\
& No & $132(40)$ \\
& alone & $38(11.5)$ \\
Living condition & With parents & $120(36.4)$ \\
& With relative & $11(3.3)$ \\
& With spouse & $161(38.8)$ \\
Source of drinking water & private tap & $223(67.6)$ \\
& Private well & $24(7.3)$ \\
& Public tap & $66(20)$ \\
Wealth status & Others & $17(5.2)$ \\
& poor & $124(37.6)$ \\
Smoking cigarette & Middle & $103(31.2)$ \\
& Rich & $103(31.2)$ \\
Doing physical exercise & yes & $7(2.1)$ \\
& No & $323(97.9)$ \\
Chewing chat & yes & $15(4.5)$ \\
& No & $315(95.5)$ \\
\hline
\end{tabular}

${ }^{+}$Spring (10) \& river (7).

Table 3. Health status related characteristics of respondents taking antiretroviral therapy in health facility of Hosanna town, Hadiya zone, South Ethiopia, from March 20 to 30/April 2014.

\begin{tabular}{ccc}
\hline & Characteristics category number (\%) & $279(84.5)$ \\
\hline Type of health facility & Hospital & $51(15.5)$ \\
& Health centre & $139(42.12)$ \\
Gastro intestinal symptoms & yes & $191(57.88)$ \\
& No & $133(40.3)$ \\
Opportunistic infections & yes & $197(59.7)$ \\
& No & $31(9.39)$ \\
Tuberculosis & yes & $299(90.61)$ \\
& No & $78(23.64)$ \\
Oral candidiasis & yes & $252(76.36)$ \\
& No & $60(18.18)$ \\
Chronic diarrhea & yes & $270(81.82)$ \\
& No & $55(16.7)$ \\
Side effect of ART & yes & $275(83.3)$ \\
& No & $282(85.5)$ \\
Adherence to ART & good & $34(10.3)$ \\
& Fair & $14(4.2)$ \\
& Poor & $70(21.21)$ \\
& I & $137(41.52)$ \\
\end{tabular}


Table 4. Dietary characteristics respondents taking antiretroviral therapy in health facility of Hosanna town, Hadiya zone, South Ethiopia, from March 20 to April 30/2014.

\begin{tabular}{|c|c|c|}
\hline \multicolumn{3}{|c|}{ Characteristics category number (\%) } \\
\hline \multirow{2}{*}{ Nutritional support } & yes & 59 (17.9) \\
\hline & No & $271(82.1)$ \\
\hline \multirow{2}{*}{ Dietary counseling } & yes & 209 (63.3) \\
\hline & No & $121(36.7)$ \\
\hline \multirow{2}{*}{ Meal frequency score } & low & $278(84.2)$ \\
\hline & High & $52(15.8)$ \\
\hline \multirow{2}{*}{ Dietary diversity score } & Inadequate & $224(67.9)$ \\
\hline & Adequate & $106(32.1)$ \\
\hline
\end{tabular}

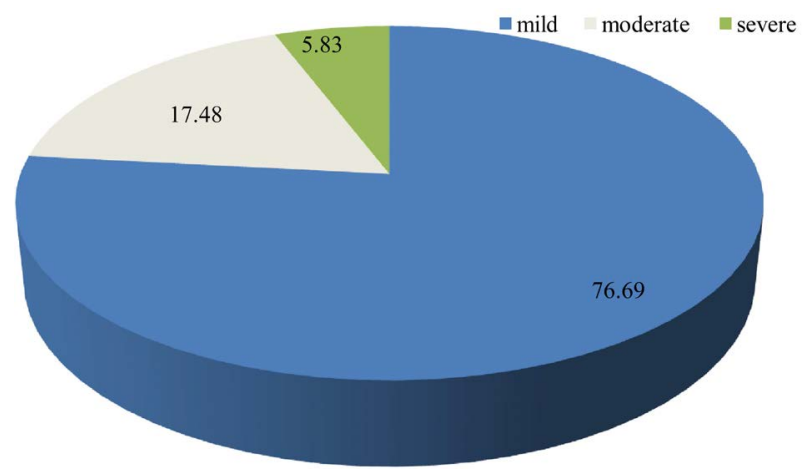

Figure 1. Food security status of respondents taking antiretroviral therapy in health facility of Hosanna town, Hadiya zone, South Ethiopia, from March 20 to April /30.

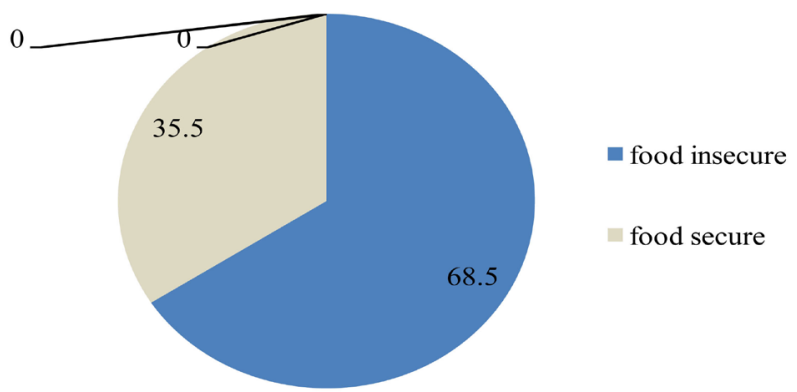

Figure 2. Degree of malnutrition among PLWHA on HAART in health facility of Hosanna town, Hadiya zone, South Ethiopia, from March 20 to April 30/2014.

collinearity diagnostics and some variables were excluded before entering to multivariable model because of multi-co linearity effect. The variables were source of drinking water with place of residence, OIS with candidiasis, diarrhea and gastrointestinal symptoms. In addition, variables did not meet the assumption of $\mathrm{X}^{2}$-tests were excluded before multivariable model.

Variables associated in the bivariate were entered to multivariable regression model by backward likely hood ratio method. Multivariable logistic regression analysis confirmed low meal frequency, inadequate dietary diversity, clinical staging three and four, opportunistic infections, nutritional support and food insecurity as potential predictor formal nutrition while controlling other covariates (Table 5). There was no interaction effect between the potential predictor variables.

WHO clinical stages had significant effect on the likelihood of malnutrition development. Individuals at clinical stage four were more than five times likely malnourished than those at stage one (AOR $=5.23,95 \% \mathrm{CI}$ : 1.42 - 19.35). Individuals at clinical stage three were 3.91 times more likely to be malnourished compared to 
Table 5. Multivariable logistic regression models predicting malnutrition (BMI $<18.5 \mathrm{~kg} / \mathrm{m}^{2}$ ) among PLWHA taking anti retroviral therapy in health facility of Hosanna town, Hadiya zone, South Ethiopia, from March 20 to April 30/2014.

\begin{tabular}{|c|c|c|c|c|c|}
\hline \multicolumn{6}{|c|}{ Malnutrition $\left(\mathrm{BMI}<18.5 \mathrm{~kg} / \mathrm{m}^{2}\right)$} \\
\hline \multirow{2}{*}{ Factors } & \multirow{2}{*}{ Category } & Yes & No & \multirow{2}{*}{ COR (95\% CI) } & \multirow{2}{*}{ AOR(95\% CI) } \\
\hline & & $\mathrm{N}(\%)$ & N (\%) & & \\
\hline \multirow{2}{*}{$\begin{array}{l}\text { Nutritional } \\
\text { support }\end{array}$} & yes & $29(28.16)$ & $30(13.22)$ & 1 & 1 \\
\hline & No & $74(71.84)$ & $197(86.78)$ & $0.39(0.22,0.69)^{*}$ & $0.45(0.23,0.89)^{*}$ \\
\hline \multirow{2}{*}{ OIS } & No & 38 (36.89) & $159(70.04)$ & 1 & 1 \\
\hline & yes & $65(63.11)$ & $68(29.96)$ & $4.00(2.45,6.53)^{*}$ & $2.62(1.49,4.59)^{*}$ \\
\hline \multirow{4}{*}{$\begin{array}{l}\text { Clinical } \\
\text { stage }\end{array}$} & Stage-I & $8(7.77)$ & $62(27.31)$ & 1 & 1 \\
\hline & Stage-II & 36 (34.95) & $101(44.49)$ & $2.76(1.21,6.33)^{*}$ & $2.1(.0 .86,5.1)$ \\
\hline & Stage-III & $51(49.51)$ & $55(24.23)$ & $5.18(3.14,16.46)^{*}$ & $3.91(1.57,9.73)^{*}$ \\
\hline & Stage-IV & $8(7.76)$ & $9(3.96)$ & $6.89(2.1,22.96)^{*}$ & $5.23(1.42,19.35)^{*}$ \\
\hline \multirow{2}{*}{$\begin{array}{c}\text { Meal } \\
\text { frequency }\end{array}$} & low & 97 (94.17) & 181 (79.74) & 1 & 1 \\
\hline & High & $6(5.83)$ & $46(20.26)$ & $0.24(0.10, .60)^{*}$ & $0.29(0.11,0.76)^{*}$ \\
\hline \multirow{2}{*}{$\begin{array}{l}\text { Dietary } \\
\text { diversity }\end{array}$} & Inadequate & 85 (82.53) & 139 (61.23) & 1 & 1 \\
\hline & Adequate & $18(7.47)$ & 88 (38.77) & $0.33(0.19,0.59)^{*}$ & $0.44(0.23,0.84)^{*}$ \\
\hline \multirow{2}{*}{$\begin{array}{c}\text { Food } \\
\text { security }\end{array}$} & Food secure & 18 (17.47) & $86(37.88)$ & 1 & 1 \\
\hline & Food insecure & 85 (82.53) & $141(62.12)$ & $2.88(1.62,5.12)^{*}$ & $2.51(1.31,4.81)^{*}$ \\
\hline
\end{tabular}

${ }^{*} \mathrm{P}$ value $<0.05$

those at stage one $(\mathrm{AOR}=3.91,95 \% \mathrm{CI}: 1.57,9.73)$.

Individuals who were diagnosed with OIS during the past six weeks were nearly 2.6 times likely to be malnourished than not infected with OIS (AOR $=2.62,95 \%$ CI: 1.49 - 4.59).

There was also a statistically significant positive association between malnutrition and food insecurity. Respondents who were food insecure were more than two times likely malnourished than food secure (AOR $=2.51$, 95\% CI: 1.31 - 4.81).

There was a statistically significant positive association between malnutrition and dietary diversity. Clients who were taking adequate diversified food $56 \%$ less likely to be malnourished than who have adequate diversified food (AOR = 0.44, 95\% CI: 0.23 - 0.84).

There was a statistically significant positive association between malnutrition and meal frequency. Respondents with high meal frequency score $71 \%$ less likely to be malnourished than who have high meal frequency $($ AOR $=0.29$, 95\% CI: $0.11-0.76)$.

Individuals who were not receiving nutritional support and care $55 \%$ less likely to be malnourished than those who were receiving nutritional support and care (AOR $=0.45$, 95\% CI: 0.23 - 0.89).

\section{Discussion}

The aim of this study was to determine magnitude of malnutrition (BMI $<18.5 \mathrm{~kg} / \mathrm{m}^{2}$ ) and identify factors associated with it among adult people on HAART at ART clinics of Hosanna town.

Results of the study showed that people on antiretroviral therapy suffer from malnutrition (BMI $<18.5 \mathrm{~kg} / \mathrm{m}^{2}$ ) at the study area. The overall prevalence of malnutrition in this study was $31.2 \%$.

Earlier studies revealed that the magnitude of under-nutrition (BMI $<18.5 \mathrm{~kg} / \mathrm{m}^{2}$ ) in Gondar University Hospital in 2007 was 27.8\% [14], and in St. Peter Hospital, Addis Ababa in 2008 was 25\% [19]. The result of the present study is higher than the results of these studies. This high rate of under-nutrition in this study could be due to high prevalence of household food insecurity (68.5\%) leading to lack of access to adequate, safe and nutritious food resulting to under-nutrition. There were also a large number of subjects (67.9\%) taking inadequate dietary diversified food which reflects low micronutrient intake; it may contribute to the pathogenesis of HIV through increasing oxidative stress and compromised immunity and indirectly resulting in under-nutrition. However, there is higher prevalence of malnutrition (BMI $<18.5 \mathrm{~kg} / \mathrm{m}^{2}$ ) at a study done in chaina and Brazil than this study. The difference could be due to these studies were done on Hospitalized AIDS patients, which may present the occurrence of increased opportunistic infections [20] [21]. 
Females were most affected by malnutrition (18.79\%). This might be due to the fact that HIV is common in women than the men. This result was consistent with an earlier similar study conducted in Dilla university hospital and Humera hospital, Ethiopia [22] [23]. A meta-analysis study conducted in 11 Sub-Saharan countries reported that the pooling prevalence estimates of HIV-related under-nutrition among HIV infected women was $10.3 \%$ [7]. It is lower than the prevalence proportion of women's malnutrition in this study. The difference could be due to the difference in socio-economic factors.

The results of this study indentified independent of other factors household food insecurity, inadequate dietary diversified diet, opportunistic infections, low meal frequency score and clinical stage four were significantly associated with malnutrition (BMI $<18.5 \mathrm{~kg} / \mathrm{m}^{2}$ ) at $\mathrm{p}<0.05$ among adult people on ART.

WHO clinical stages had significant effect on the likelihood of malnutrition development. Individuals at clinical stage four were more than five times likely malnourished than those at stage one (AOR $=5.23,95 \%$ CI: 1.42 - 19.35). Respondents at clinical stage three were 3.91 times more likely malnourished than those at stage one (AOR = 3.91, 95\% CI: 1.57, 9.73).

This result is consistent with an earlier similar study conducted in dilla university hospital [22]. Similarly, study done in Uganda shows PLWHA taking ART at WHO clinical stage four characterized by sever wasting chronic fever, chronic diarrhea and weight loss greater than $10 \%$ from baseline [24].

Regarding to OIS, individuals who were diagnosed with OIS during the past six weeks were more nearly 2.6 times likely malnourished than not diagnosed with OIS (AOR $=2.62$, 95\% CI: 1.49 - 4.59). This result is in line with earlier similar study conducted in Dilla university hospital [22]. Likewise, this finding is well supplemented by similar studies conducted in Kenya [25].

A study conducted in Jimma University Hospital, Ethiopia revealed 63.0\% of PLWHA on HAART were food insecure [26]. There was a statistically significant positive association between malnutrition and food insecurity in this study. Respondents who were food insecure were more than two times likely malnourished as compared to food secure individuals (AOR $=2.51,95 \% \mathrm{CI}: 1.31-4.81$ ). This result was consistent with study conducted at Humera Hospital [23]. Moreover, the result of this study consistent with an earlier similar study conducted in Uganda in 2012 among PLWHA on ART that those who were food insecure were more likely to be undernourished [24].

There was a statistically significant association between malnutrition and dietary diversity. Clients who had adequate diversified food were $56 \%$ less likely to be malnourished than who had inadequate diversified food (AOR $=0.44,95 \%$ CI: $0.23-0.84$ ). This result was consistent with an earlier similar study conducted in Humera referral hospital [23]. Moreover, a study conducted in Mozambique supports the result of this study [27].

The finding of this study showed low meal frequency had significant positive association with malnutrition. Respondents with high meal frequency score $71 \%$ likely to be malnourished than who had low meal frequency (AOR $=0.29,95 \%$ CI: $0.11-0.76)$. A study conducted in Dire Dewa supports this finding; in which increased meal frequency was associated with increased BMI [16]. Moreover, the finding from this study is supported by a nutrition counselling card for PLWHA [28]. Limited similar studies exist to discuss more on this issue.

Other important finding of this study, which has implication for practical programming, is the negative relationship of nutritional support and under-nutrition. In this study participants who were not taking nutritional care and support were $55 \%$ less likely to be undernourished than those who were taking nutritional care and support $(\mathrm{AOR}=0.45,95 \%$ CI: 0.23, 0.89).

However, a study done in Haiti demonstrated that food assistance among PLWHA on ART significantly improved their BMI [29]. This disagreement between the findings could be individuals experiencing food insecurity were probably shared nutritional support among household members or sold to get money.

Regarding the limitation of this study, recall bias may limit subjects to remember components of their nutritional intake and respondents may not tell the real information about their food security status due to the need for aid. In addition, data on dietary intake may be affected by seasonal variation.

\section{Conclusion}

In conclusion, the prevalence of overall malnutrition was high among adult people on ART despite of HAART in the study area. Existing care and treatment clinics that provide nutritional support to PLWHA on ART do not appear to address the issues of malnutrition. Predictors of malnutrition were food insecurity, inadequate diversified diet, low meal frequency, clinical stage four and three, presence of opportunistic infections and getting nu- 
tritional support (plumpy nut). Only ART is not enough to improve the health status of PLWHA on HAART. Further, intervention initiatives should focus on improving household food security, diversity of diet, meal frequency, clinical staging and prevention and control of opportunistic infections in adult HIV infected individuals receiving highly active antiretroviral therapy to address the problem of malnutrition.

\section{Competing Interests}

We declare that we do not have competing interests.

\section{Authors' Contributions}

M.A., C.H. and H.J. participated in the conception, design of the study, analysis and interpretation of the data. M.A. drafted the manuscript and coordinated the data collection. C.H. and H.J. involved in the review of the manuscript. All authors read and approved the final manuscript.

\section{Acknowledgements}

We gratefully acknowledge the study participants, supervisors and data collectors for the information provided, without which this work would not have been possible. The funders had no role in the study.

\section{References}

[1] World Food Programme (2005) A Manual: Measuring and Interpreting Malnutrition and Mortality. Rome.

[2] Nerad, J. and Romeyn, M. (2004) General Nutrition Management in Patients Infected with HIV. Clinical Infectious Diseases, 36.

[3] Nutritional Care and Support for People Living with HIV/AIDS Training Course. WHO, Switzerland, 2009.

[4] WHO, UNAIDS and UNICEF (2011) GLOBAL HIV/AIDS Response Epidemic Update and Health Sector Progress towards Universal Access. Progress Report.

[5] EDHS: Central Statistical Agency (CSA): Ethiopia, Addis Ababa, CSA, 2011.

[6] USAID, SARA and FANTA (2009) A Whole Some Approach: Nutrition and HIV/AIDS.

[7] Olalekan, A.U. (2008) Prevalence and Pattern of HIV-Related Malnutrition among Women in Sub-Saharan Africa: A Meta-Analysis of Demographic Health Surveys. BMC Public Health, 8, 226. http://www.biomedcentral.com/1471-2458/8/226

[8] The International Bank for Reconstruction and Development/the World Bank (2007) HIV/AIDS, Nutrition, and Food Security: What We Can Do, a Synthesis of International Guidance. http://siteresources.worldbank.org/NUTRITION/Resources/281846

[9] Joint United Nations Programme on HIV/AIDS (UNAIDS) (2007) AIDS Epidemic Update. UNAIDS and the World Health Organization, Geneva.

[10] Crush, J., Frayne, B. and Grant, M. (2006) The Regional Network on HIV/AIDS, Livelihoods and Food Security/International Food Policy Research Institute/Southern African Migration Project. IFPRI, Washington.

[11] Piwoz, E.G. and Preble, E.A. (2009) HIV/AIDS and Nutrition, a Review of the List \& Recommendations for Nutritional Care \& Support in Sub-Saharan Africa. Support for Analysis \& Research in Africa (SARA) Project Academy for Educational Development, Washington DC. http://repository.forcedmigration.org/show_metadata.jsp?pid=fmo:3406

[12] Castleman, T., Seumo-Fosso, E. and Cogill, B. (2004) Food and Nutrition Implications of Antiretroviral Therapy in Resource Limited Settings. Food and Nutrition Technical Assistance Project (FANTA) Academy for Educational Development, Washington DC.

[13] World Bank and UNAIDS (2009) The Global Economic Crisis and HIV Prevention and Treatment Programmes: Vulnerabilities and Impact.

[14] Belaynew, W., Yigzaw, K. and Anwar, Y. (2010) Nutritional Status of Adults Living with HIV/AIDS at the University of Gondar Referal Hospital Northwest Ethiopia. Ethiopian Journal of Health and Biomedical Science, 3, 3-14.

[15] FAO (2007) Nutrition and Consumer Protection Division: Guidelines for Measuring Household and Individual Dietary Diversity. FAO, Rome.

[16] Seifu, A. (2007) Impact of Food and Nutrition Security on Adherence to Anti-Retroviral Therapy (ART) and Treatment Outcomes among Adult PLWHA in Dire. Dawa Provisional Administration, Dire Dawa. 
[17] Coates, J., Swindale, A. and Bilinsky, P. (2007) Household Food Insecurity Access Scale (HFIAS) for Measurement of Household Food Access: Indicator Guide Version 3. Food and Nutrition Technical Assistance Project Academy for Educational Development, Washington DC.

[18] WHO (1995) Physical Status: The Use and Interpretation of Anthropometry. Report of a WHO Expert Committee. WHO Technical Report Series 854. World Health Organization, Geneva.

[19] Fufa, H., Umeta, M., Taffesse, S., Mokhtar, N. and Aguenaou, H. (2009) Nutritional and Immunological Status and Their Associations among HIV-Infected Adults in Addis Ababa, Ethiopia. Food and Nutrition Bulletin, 30, $227-232$.

[20] Wen, H., Hua, J. and Wei, C. (2011) Malnutrition in Hospitalized People Living with HIV/AIDS: Evidence from a Cross-Sectional Study from Chengdu, China. Journal of Clinical Nutrition, 20, 544-550.

[21] Andrade, C.S., Jesus, R.P., Andrade, T.B., Oliveira, N.S., Nabity, S.A. and Ribeiro, G.S. (2012) Prevalence and Characteristics Associated with Malnutrition at Hospitalization among Patients with Acquired Immunodeficiency Syndrome in Brazil, 2012. http://www.ncbi.nlm.nih.gov/pubmed/23144941 https://wfpha.confex.com/wfpha/2012/webprogram/Paper10162.html

[22] Solomon, H., Girma, T. and Henok, T. (2013) Malnutrition: Prevalence and Its Associated Factors in PLWHA, in Dilla University Hospital. Archives of Public Health, 71, 13. http://www.ncbi.nlm.nih.gov/pubmed/23759075 http://dx.doi.org/10.1186/0778-7367-71-13

[23] Tsegazeab, H., Walelgn, W. and Desalegn, T. (2013) Under Nutrition among HIV Positive Women in Humera Hospital, Ethiopia: Anti Retro Viral Alone Is Notenough. BMC Public Health, 13, 943.

[24] Rawat, R., Kadiyala, S. and McNamara, E. (2010) The Impact of Food Assistance on Weight Gain and Disease Progression among HIV-Infected Individuals Accessing AIDS Care and Treatment Services in Uganda. BMC Public Health, 10, 316. http://dx.doi.org/10.1186/1471-2458-10-316

[25] Agatha, C., Mary, K., Grace, M. and Rose, K. (2011) Body Composition and CD4 Cell Count of HIV Sero-Positive Adults Attending Out-Patient Clinic in Chulaimbo Sub-District Hospital, Kenya. Pakistan Journal of Nutrition, 10, 582-588. http://dx.doi.org/10.3923/pjn.2011.582.588

[26] Ayele, T., Tefera, B., Fisehaye, A. and Sibhatu, B. (2012) Food Insecurity and Associated Factors among HIV-Infected Individuals Receiving Highly Active Antiretroviral Therapy in Jimma Zone Southwest Ethiopia. Nutrition Journal, 11, 51.

[27] Scarcella, P., Buonomo, E., Zimba, I., Doro Altan, A.M., Germano, P., Palombi, L. and Marazzi, M.C. (2011) The Impact of Integrating Food Supplementation, Nutritional Education and HAART on the Nutritional Status of Patients Living with HIV/AIDS in Mozambique: Results from the DREAM Programme. Igiene e Sanità Pubblica, 67, 41-52. http://www.ncbi.nlm.nih.gov/pubmed/21468153.

[28] Nutrition for PLWHA - Counselling Cards Is a Publication of Regional Centre for Quality of Health Care (RCQHC), Kampala - Uganda, 2004.

[29] Louise, C., Yuchiao, C., Gregory, J. and Kenneth, A. (2010) Food Assistance Is Associated with Improved Body Mass Index, Food Security and Attendance at Clinic in an HIV Program in Central Haiti: A Prospective Observational Cohort Study. AIDS Research and Therapy, 7, 1-8. 
Scientific Research Publishing (SCIRP) is one of the largest Open Access journal publishers. It is currently publishing more than 200 open access, online, peer-reviewed journals covering a wide range of academic disciplines. SCIRP serves the worldwide academic communities and contributes to the progress and application of science with its publication.

Other selected journals from SCIRP are listed as below. Submit your manuscript to us via either submit@scirp.org or Online Submission Portal.
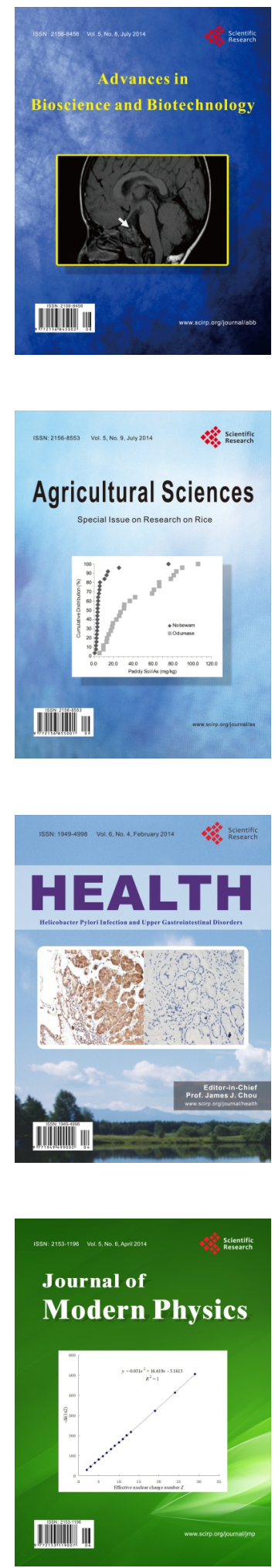
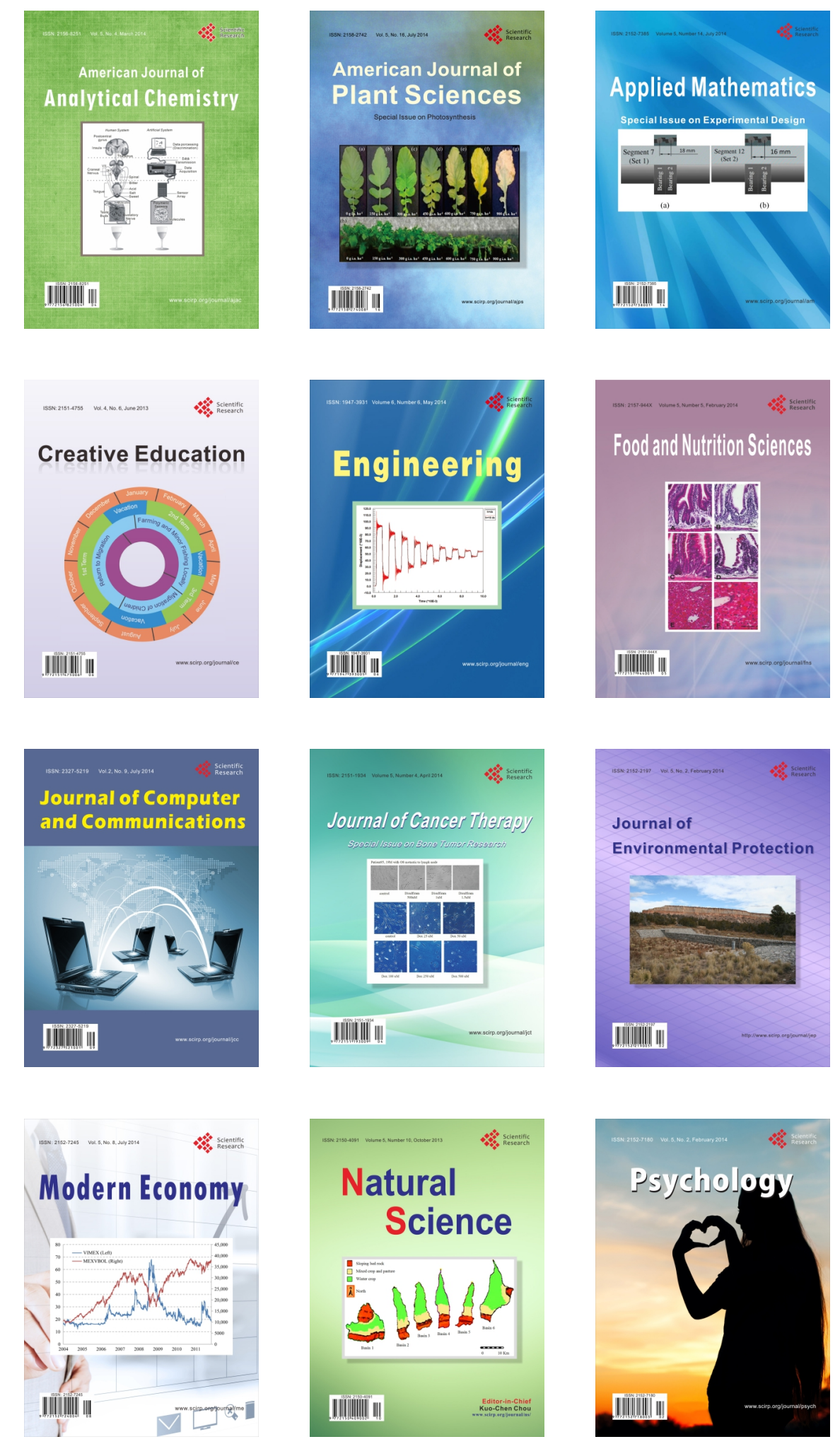